\title{
Long-term monitoring of primary production in coastal waters by an improved natural fluorescence method
}

\author{
Takashi Yoshikawa ${ }^{1,2, *}$, Ken Furuya ${ }^{1}$ \\ ${ }^{1}$ Department of Aquatic Bioscience, Graduate School of Agricultural and Life Sciences, The University of Tokyo, Bunkyo, \\ Tokyo 113-8657, Japan \\ ${ }^{2}$ Present address: Fisheries Laboratory, Kinki University, Nakamachi, Nara 631-8505, Japan
}

\begin{abstract}
In order to apply the natural fluorescence method for the long-term monitoring of chl $a$ and primary production, the seasonal variation in the light absorption coefficient of phytoplankton $\left(a^{*}{ }_{\mathrm{ph}}\right)$, maximum quantum yield ratio of photosynthesis to fluorescence $\left[\left(\phi_{\mathrm{c}} / \phi_{\mathrm{f}}\right)_{\max }\right]$, and its light saturation index $\left(\mathrm{k}_{\mathrm{cf}}\right)$ were examined. The mooring of a natural fluorescence sensor was conducted during winter to early spring (January to April 1998), late spring (May 2000) and summer (July to August 2000 ) at a station in Otsuchi Bay on the north east coast of Japan. The bio-optical parameters, $a^{*}{ }_{\mathrm{ph}}$ $\left(\phi_{\mathrm{c}} / \phi_{\mathrm{f}}\right)_{\max }$ and $\mathrm{k}_{\mathrm{cf}}$, were measured by water sampling and incubation experiments twice a week. The temporal variation in $a^{*}{ }_{p h}$ was expressed as an exponential of chl $a$. This relationship varied seasonally. The variations in $\left(\phi_{\mathrm{c}} / \phi_{\mathrm{f}}\right)_{\max }$ were related to chl $a$ during winter to early spring, and to chl $a$ and temperature during late spring and summer. The value of $\mathrm{k}_{\mathrm{cf}}$ was relatively low and stable during the winter and early spring; it reached higher values during late spring to summer, when temperature and light intensities were also higher. Based on these relationships, the long-term monitoring of chl a and primary production from natural fluorescence was realized in coastal water where environmental conditions and phytoplankton abundance fluctuated markedly. By developing algorithms in various areas and seasons, as the present study has shown, the natural fluorescence method is expected to be useful for continuous monitoring of primary production, with a high spatial resolution by a mooring web of sensors, even in coastal waters.
\end{abstract}

KEY WORDS: Natural fluorescence $\cdot$ Primary production $\cdot \mathrm{Chl} a \cdot$ Light absorption of phytoplankton · Coastal waters

Resale or republication not permitted without written consent of the publisher

\section{INTRODUCTION}

Recently, several bio-optical approaches for phytoplankton primary production measurement, such as the remote sensing of ocean color from satellites (Platt \& Sathyendranath 1988, Morel \& André 1991, Behrenfeld \& Falkowski 1997), and natural and variable fluorometers with buoy systems (Chamberlin et al. 1990, Kolber \& Falkowski 1993), have been developed. These bio-optical approaches provide spatio-temporally continuous data, as an alternative to the traditional and standard ${ }^{14} \mathrm{C}$ incubation technique on ships.
The latter technique has been found to be time consuming, laborious and limited in spatio-temporal resolution. The natural fluorescence method is suitable for long-term monitoring by moorings and drifters, as a natural fluorometer requires low battery power and less frequent maintenance compared with variable fluorometers configured with an excitation beam source.

Natural fluorescence is the solar-stimulated emission of fluorescence from phytoplankton chl a centered at $683 \mathrm{~nm}$ (Collins et al. 1985). The photosynthetic rate can be derived from measurements of natural fluorescence if the quantum yield ratio of photosynthesis and 
fluorescence $\left(\phi_{\mathrm{c}} / \phi_{\mathrm{f}}\right)$ is given. Chamberlin et al. (1990) demonstrated that the variability in $\phi_{\mathrm{C}} / \phi_{\mathrm{f}}$ primarily depends on the photosynthetically available radiation $\left(E_{\text {PAR }}^{\circ}\right)$. Thereafter, a number of studies supported natural fluorescence as a means for the rapid assessment of photosynthesis (Chamberlin \& Marra 1992, Stegmann et al. 1992, Lizotte \& Priscu 1994, GarciaMendoza \& Maske 1996). However, $\phi_{\mathrm{c}} / \phi_{\mathrm{f}}$ changes with temperature (Chamberlin \& Marra 1992) and nutrients (Lizotte \& Priscu 1994), along with light intensity. There are also regional variations in the maximum value of $\phi_{\mathrm{c}} / \phi_{\mathrm{f}}\left[\left(\phi_{\mathrm{c}} / \phi_{\mathrm{f}}\right)_{\max }\right]$ and its light saturation index $\left(\mathrm{k}_{\mathrm{cf}}\right)$, the bio-optical parameters in the equation of Chamberlin et al. (1990) and Stegmann et al. (1992). Furthermore, almost all studies about the natural fluorescence method have been conducted as snapshots of its vertical profiles, and there is little knowledge about seasonal variations in $\left(\phi_{\mathrm{c}} / \phi_{\mathrm{f}}\right)_{\max }$ and $\mathrm{k}_{\mathrm{cf}}$. Thus, the temporal fluctuations and unpredictability of the bio-optical parameters have prevented us from extrapolating the natural fluorescence method for long-term observations. This is particularly the case in coastal waters, where environmental conditions fluctuate significantly on the time scales of hours to days due to tidal currents, inflow of fresh water, etc. (Winter et al. 1975).

The present study aimed to apply the natural fluorescence method for the long-term monitoring of chl $a$ and primary production by examining variations in the bio-optical parameters during various seasons in the coastal waters of Japan. In previous studies, $\phi_{\mathrm{c}} / \phi_{\mathrm{f}}$ was plotted against $E_{\text {PAR, }}^{\circ}$ and the parameters $\left(\phi_{\mathrm{c}} / \phi_{\mathrm{f}}\right)_{\max }$ and $\mathrm{k}_{\mathrm{cf}}$ were indirectly derived by curve fitting with the equation of Chamberlin et al. (1990). Also in those studies, the data from various sites and depths, where the dominant physical or chemical processes were different, were pooled. Therefore, it was difficult to determine the cause of the change in the above parameters other than light intensity. In the present study, we obtained $a^{*}{ }_{p h},\left(\phi_{\mathrm{c}} / \phi_{\mathrm{f}}\right)_{\max }$ and $\mathrm{k}_{\mathrm{cf}}$ directly from each measurement of the photosynthesis-irradiance $(P-E)$ curve parameters, maximum quantum yield $\left(\phi_{\mathrm{c}} \max \right)$ and light saturation index $\left(E_{\mathrm{k}}\right)$, and examined the relationship between these parameters and environmental factors.

\section{MATERIALS AND METHODS}

Theoretical background. Chl a can be estimated from the natural fluorescence rate, $F_{\mathrm{f}}$, and the photosynthetically available radiation (PAR; 400 to $700 \mathrm{~nm}$ ), $E_{\text {PAR, }}^{\circ}$ with the quantum yield of fluorescence, $\phi_{\mathrm{f}}$, and the chl a specific absorption coefficients of phytoplankton, $a^{*}$ ph (Kiefer et al. 1989, see Table 1 for explanations of symbols and units).
Table 1. Definitions of symbols used in the text

\begin{tabular}{|c|c|}
\hline$F_{\mathrm{f}}$ & Natural fluorescence (NF) rate, $\mu$ mol photon $\mathrm{m}^{-3} \mathrm{~s}^{-1}$ \\
\hline$F_{\mathrm{c}}$ & Photosynthesis rate, $\mu \mathrm{mol} \mathrm{C} \mathrm{m}^{-3} \mathrm{~s}^{-1}$ \\
\hline $\operatorname{chl} a$ & Chl a concentration, $\mathrm{mg} \mathrm{m}^{-3}$ \\
\hline$E_{\mathrm{PAR}}^{\circ}$ & $\begin{array}{l}\text { Scalar irradiance of photosynthetically avail- } \\
\text { able radiation, } \mu \mathrm{mol} \text { photon } \mathrm{m}^{-2} \mathrm{~s}^{-1}\end{array}$ \\
\hline$L_{\mathrm{u} \text { chl }}$ & $\begin{array}{l}\text { Upwelling radiance of natural fluorescence, } \\
\mu \mathrm{mol} \text { photon } \mathrm{m}^{-2} \mathrm{str}^{-1} \mathrm{~s}^{-1}\end{array}$ \\
\hline$a^{*}{ }_{\mathrm{ph}}$ & $\begin{array}{l}\text { Chl a specific absorption coefficients of phyto } \\
\text { plankton, } \mathrm{m}^{2}(\mathrm{mg} \mathrm{chl} \mathrm{a})^{-1}\end{array}$ \\
\hline $\mathrm{k}_{\mathrm{PAR}}$ & Diffuse attenuation coefficients for $E_{\mathrm{PAR}}^{\circ} \mathrm{m}^{-1}$ \\
\hline$a_{\text {chl }}$ & Absorption coefficients for $L_{\mathrm{u} \text { chl }}, \mathrm{m}^{-1}$ \\
\hline$\phi_{\mathrm{f}}$ & $\begin{array}{l}\text { Quantum yield of natural fluorescence, mol } \\
\text { photon emitted (mol photon absorbed) })^{-1}\end{array}$ \\
\hline$\phi_{\mathrm{c}}$ & $\begin{array}{l}\text { Quantum yield of photosynthesis, mol C fixed } \\
\text { (mol photon absorbed })^{-1}\end{array}$ \\
\hline$\phi_{\mathrm{c} \max }$ & $\begin{array}{l}\text { Maximum quantum yield of photosynthesis, mol } \\
\text { C fixed (mol photon absorbed) })^{-1}\end{array}$ \\
\hline$\left(\phi_{\mathrm{C}} / \phi_{\mathrm{f}}\right)_{\max }$ & $\begin{array}{l}\text { Maximum ratio of } \phi_{\mathrm{c}} \text { to } \phi_{\mathrm{f}} \text {, mol C fixed (mol } \\
\text { photon emitted })^{-1}\end{array}$ \\
\hline$E_{\mathrm{k}}$ & $\begin{array}{l}\text { Light saturation index for } \phi_{\mathrm{cmax}}, \mu \mathrm{mol} \text { photon } \\
\mathrm{m}^{-2} \mathrm{~s}^{-1}\end{array}$ \\
\hline $\mathrm{k}_{\mathrm{cf}}$ & $\begin{array}{l}\text { Light saturation index for }\left(\phi_{\mathrm{c}} / \phi_{\mathrm{f}}\right)_{\max }, \mu \mathrm{mol} \text { photon } \\
\mathrm{m}^{-2} \mathrm{~s}^{-1}\end{array}$ \\
\hline
\end{tabular}

$$
\text { Chl } a=F_{\mathrm{f}} /\left(\phi_{\mathrm{f}} a^{*}{ }_{\mathrm{ph}} E_{\mathrm{PAR}}^{\circ}\right)
$$

where $\phi_{\mathrm{f}}$ and $a^{*}{ }_{\mathrm{ph}}$ are constants. $a^{*}$ ph is the simple averaging of the $a^{*}{ }_{\mathrm{ph}}(\lambda)$ over the PAR without any weighting function. $F_{\mathrm{f}}$ is a measure of light per unit volume, assuming the source has a spectral distribution similar to chlorophyll fluorescence, and calculated from its upward radiance, $L_{\mathrm{u}}$ chl, recorded by the sensor.

$$
F_{\mathrm{f}}=4 \pi\left(\mathrm{k}_{\mathrm{PAR}}+a_{\mathrm{chl}}\right) L_{\mathrm{u} \text { chl }}
$$

where the term $4 \pi$ is a geometric constant with units of steradians, used to convert the limited field of view of a sensor to a volume fluorescence. $\mathrm{k}_{\mathrm{PAR}}$ is the diffuse attenuation coefficient for $E_{\text {PAR, }}^{\circ}$ and $a_{\text {chl }}$ is the absorption coefficient for water and its constituents, all weighted over the emission spectrum of chlorophyll. Attenuation of the fluorescence signal as a function of distance away from the detector is expressed as the sum $\mathrm{k}_{\mathrm{PAR}}+a_{\mathrm{chl}}$.

Chamberlin et al. (1990) proposed an empirical formula for estimating the photosynthetic rate $\left(F_{\mathrm{c}}\right)$ based on the observation that variations in the ratio of the quantum yield of photosynthesis and fluorescence $\left(\phi_{\mathrm{C}} / \phi_{\mathrm{f}}\right)$ primarily depend on $E_{\mathrm{PAR}}^{\circ}$.

$$
F_{\mathrm{c}}=\left(\phi_{\mathrm{C}} / \phi_{\mathrm{f}}\right)_{\max } \mathrm{k}_{\mathrm{cf}} /\left(\mathrm{k}_{\mathrm{cf}}+E^{\circ}{ }_{\mathrm{PAR}}\right) F_{\mathrm{f}}
$$

They defined $\left(\phi_{\mathrm{c}} / \phi_{\mathrm{f}}\right)_{\max }$ and $\mathrm{k}_{\mathrm{cf}}$ as constants, each representing the maximum value of $\left(\phi_{\mathrm{c}} / \phi_{\mathrm{f}}\right)$, and the light saturation index of $\left(\phi_{\mathrm{c}} / \phi_{\mathrm{f}}\right)_{\max }$, respectively. 
Mooring of the natural fluorescence sensor. All observations and measurements were conducted at a station located in the central region of Otsuchi Bay $\left(39^{\circ} 20^{\prime} \mathrm{N}, 141^{\circ} 56^{\prime} \mathrm{E}\right.$, Fig. 1$)$, a subarctic ria, ca. $8 \mathrm{~km}$ long and $2 \mathrm{~km}$ wide, opening into the north west Pacific Ocean during the winter to spring bloom period (19 January to 27 April 1998), and during late spring and summer (12 to 29 May, 19 July to 9 August 2000). Furuya et al. (1993) showed that nutrient supply, and the abundance and primary production of phytoplankton, were mainly controlled by the water-mass exchange between the inside and outside of the bay. Kawamiya et al. (1996) confirmed this mechanism by using a simulation model coupling the physical and biological parameters. The water-mass exchange is driven mainly by the seasonal northwest wind during the winter to early spring, and by the difference in water density between inside and outside the bay during the summer (Shikama 1980, Shikama 1990).

The upward radiance of natural fluorescence, $L_{\mathrm{u} \text { chl }}$, the scalar irradiance over the PAR, $E_{\mathrm{PAR}}^{\circ}$, and water temperature were recorded at $10 \mathrm{~min}$ intervals by the natural fluorescence sensor, INF-300 (Biospherical Instruments), moored at $7.5 \mathrm{~m}$ depth at the station. The biotic fouling on the sensor was removed every 1 to $2 \mathrm{wk}$. The INF-300 has a radiance detector with a relatively wide spectral response function that follows closely the emission spectrum for chlorophyll (i.e. about a half-maximum bandwidth of $25 \mathrm{~nm}$, centered at $683 \mathrm{~nm}$ ). The mooring depth was chosen to coincide with the depth at which spring blooms often occur. The effect of the scattered sunlight on the detection of natural fluorescence is negligible below $5 \mathrm{~m}$ in depth (Kiefer et al. 1989), and there is a risk of a passing fishing boat hitting the sensor if placed at shallower depths. That the effect of backscattering was small at the moored depth was concluded after comparing the

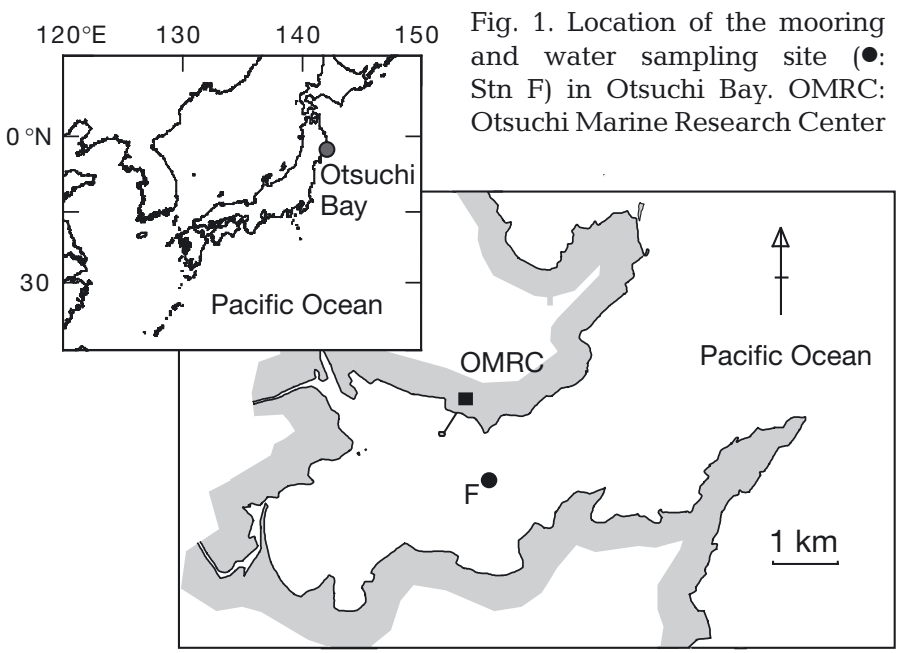

vertical profiles of the upward radiance at $683 \mathrm{~nm}$ by the PRR-600 and that of chl a measured by water sampling.

Bio-optical parameters. Water sampling at the mooring depth of the sensor was conducted 2 to 3 times $\mathrm{wk}^{-1}$, and used for the measurement of $a^{*}$ ph photosynthesis-irradiance $(P-E)$ curves, chl $a$, nutrients and pigments. Temperature and salinity profiles were obtained from STD casts (Alec Electric), and down-

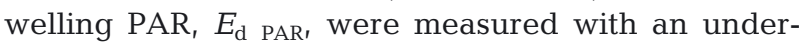
water spectroradiometer (PRR600, Biospherical) during water sampling.

The chl a specific absorption coefficient spectrum, $a^{*}{ }_{p h}(\lambda)$, and its simple spectral mean, $a^{*}{ }_{p h}$, were measured by the quantitative filter technique (QFT) method (Kishino et al. 1985). De-pigmentation of the particulate on the filter was made by extraction with methanol. The optical density of phytoplankton was obtained by subtracting that of the detritus from the total particulate. These optical densities on the filter were converted into those in the suspension using the equation described in Cleveland \& Weidemann (1993).

The quantum yield of fluorescence, $\phi_{\mathrm{f}}$, was determined from the measurements of $F_{\mathrm{f},} E_{\mathrm{PAR}}^{\circ} \mathrm{chl} a$ and $a^{*}{ }_{p h}$ in Eq. (1). The absorption coefficient over the emission spectrum of chlorophyll, $a_{\text {chll }}$, was calculated for the peak wavelength of fluorescence emission at $683 \mathrm{~nm}, a(683)$ (Kiefer et al. 1989, Chamberlin et al. 1990). $a(683)$ is the sum of the absorption by pure water $\left[a_{\mathrm{w}}(683)\right]$, total particles $\left[a_{\mathrm{p}}(683)\right]$ and yellow substances [a $(683)]$. $a_{\mathrm{p}}(683)$ was measured by the QFT method as above. $a_{\mathrm{w}}(683)$ is a constant of 0.46 (Smith \& Baker 1981) and $a_{\mathrm{y}}(683)$ is negligible (Kishino et al. 1984). The diffuse attenuation coefficients for PAR, $\mathrm{k}_{\mathrm{PAR}}$, were calculated from the vertical profile of the downward PAR, $E_{\text {d PAR, }}$ by the PRR600. The value of $\mathrm{k}_{\mathrm{PAR}}$ for $E_{\mathrm{d} \text { PAR }}$ is almost equivalent to that for $E_{\mathrm{PAR}}^{\circ}$ which is measured by the INF300, except for the heavily turbid waters (Kirk 1994).

The photosynthetic rates under various light intensities were determined from the uptake of $\mathrm{H}^{14} \mathrm{CO}_{3}{ }^{-}$with incubation in a photosynthetron (Lewis \& Smith 1983). A total of 100 to $200 \mu \mathrm{Ci}$ of $\mathrm{NaH}^{14} \mathrm{CO}_{3}{ }^{-}$was added to a $50 \mathrm{ml}$ water sample in a $100 \mathrm{ml}$ polycarbonate bottle, and $2 \mathrm{ml}$ was dispensed into 21 scintillation glass vials. Samples were then incubated for $30 \mathrm{~min}$ in a photosynthetron with a light gradient of up to $2500 \mu \mathrm{mol}$ photons $\mathrm{m}^{-2} \mathrm{~s}^{-1}$ using a halogen lamp. The temperature was controlled at an in situ level. After driving off the inorganic carbon in the samples by acidification, $5.5 \mathrm{ml}$ of an Aquasol-II cocktail was added to the water samples with no filtration, and the total radioactivity of both particle and dissolved organic carbon in the samples were counted. Photosynthesis-irradiance $(P-E)$ parameters were derived by fitting with the hyperbolic 
tangent type function, as proposed by Jassby \& Platt (1976):

$$
\begin{aligned}
P^{*} & =P^{*}{ }_{\max } \tanh \left(E^{\circ}{ }_{\mathrm{PAR}} / E_{\mathrm{k}}\right) \\
& =\alpha^{*} E_{\mathrm{k}} \tanh \left(E_{\mathrm{PAR}}^{\circ} / E_{\mathrm{k}}\right)
\end{aligned}
$$

where $P^{*}\left[\mathrm{mg} \mathrm{C}(\mathrm{mg} \mathrm{chl} a)^{-1} \mathrm{~h}^{-1}\right]$ is the photosynthetic rate normalized to chl $a$ at irradiance $E^{\circ}{ }_{\text {PAR }} P^{*}{ }_{\text {max }}$ is the maximum rate of photosynthesis at the light-saturated rate under these conditions, $\alpha^{*}\left(\left[\mathrm{mg} \mathrm{C}(\mathrm{mg} \mathrm{chl} \mathrm{a})^{-1} \mathrm{~h}^{-1}\right]\right.$ $\left[\mu \mathrm{mol} \mathrm{m} \mathrm{m}^{-2} \mathrm{~s}^{-1}\right]^{-1}$ ) is the initial slope of the $P$ - $E$ curve at the limiting light levels, and $E_{\mathrm{k}}$ is the light saturation parameter. The maximum quantum yield of photosynthesis, $\phi_{\mathrm{c} \max }\left[\mathrm{mol} \mathrm{C}(\mathrm{mol} \text { photon })^{-1}\right]$ is:

$$
\phi_{\mathrm{c} \max }=0.0231 \alpha^{*} / a^{*}{ }_{\mathrm{ph}}
$$

where 0.0231 is the constant for converting $\mathrm{mg} \mathrm{C}$ to mol $\mathrm{C}$, umol photon to mol photon, and $\mathrm{h}$ to $\mathrm{s}$. The Michaelis-Menten type Eq. (3) for estimating the primary production is converted into the hyperbolic tangential equation given by:

$$
F_{\mathrm{c}}=\left(\phi_{\mathrm{c}} / \phi_{\mathrm{f}}\right)_{\max } \mathrm{k}_{\mathrm{cf}} / E^{\circ}{ }_{\mathrm{PAR}} \tanh \left(E_{\mathrm{PAR}}^{\circ} / \mathrm{k}_{\mathrm{cf}}\right) F_{\mathrm{f}}
$$

where $\left(\phi_{\mathrm{c}} / \phi_{\mathrm{f}}\right)_{\max }$ is obtained by dividing $\phi_{\mathrm{c} \max }$ with $\phi_{\mathrm{f}}$ and $\mathrm{k}_{\mathrm{cf}}$ is equivalent to $E_{\mathrm{k}}$ in Eq. (4), assuming that $\phi_{\mathrm{f}}$ is independent from $E_{\mathrm{PAR}}^{\circ}$.

Chl a was determined fluorometrically (Turner design) for particles collected on $25 \mathrm{~mm}$ Whatman GF/F filters and extracted by N,N-Dimethylformamide (Suzuki \& Ishimaru 1990). Pigment composition of phytoplankton was determined by HPLC following the protocol described by Furuya et al. (1998). Chlorophylls and carotenoids detected included $\operatorname{chl} a$, chl $b$, chl $c_{1}$ and $c_{2}$, peridinin, 19'-butanoyloxyfucoxanthin, fucoxanthin, 19'-hexanoyloxyfucoxanthin, neoxantin, prasinoxanthin, violaxanthin, diadinoxanthin, alloxanthin, zeaxanthin and $\beta$-carotene. The class-level taxonomical composition was estimated by CHEMTAX, a matrix factorization program (Mackey et al. 1996). The initial ratio of each diagnostic marker pigment to chl a was derived after minor modifications following Mackey et al. (1996) and (Ramaiah et al. 2001).

Samples for nutrient concentration analysis were frozen immediately and stored at $-20^{\circ} \mathrm{C}$ until analysis. Concentrations of dissolved inorganic nitrate, ammonium and phosphate were determined using an Auto Analyzer II (Technicon).

\section{RESULTS}

\section{Hydrographic conditions}

Winter to early spring

The water temperatures at $7.5 \mathrm{~m}$ depth ranged between 6 and $10^{\circ} \mathrm{C}$. The water column was vertically well mixed, as suggested by the uniform water temperature distribution until March, and a weak thermal stratification was observed below $5 \mathrm{~m}$ depth in April. Chl $a$, determined by water sampling, showed marked fluctuations, with values ranging from 0.4 to $11.4 \mathrm{mg} \mathrm{m}^{-3}$. Diatoms were the most dominant group during the spring bloom period, as observed from the analysis of diagnostic marker pigments (Ramaiah et al. 2001). Nitrate was the most abundant type of dissolved inorganic nitrogen measured, with levels varying from undetectable $(<0.05 \mu \mathrm{M})$ to $>10 \mu \mathrm{M}$.
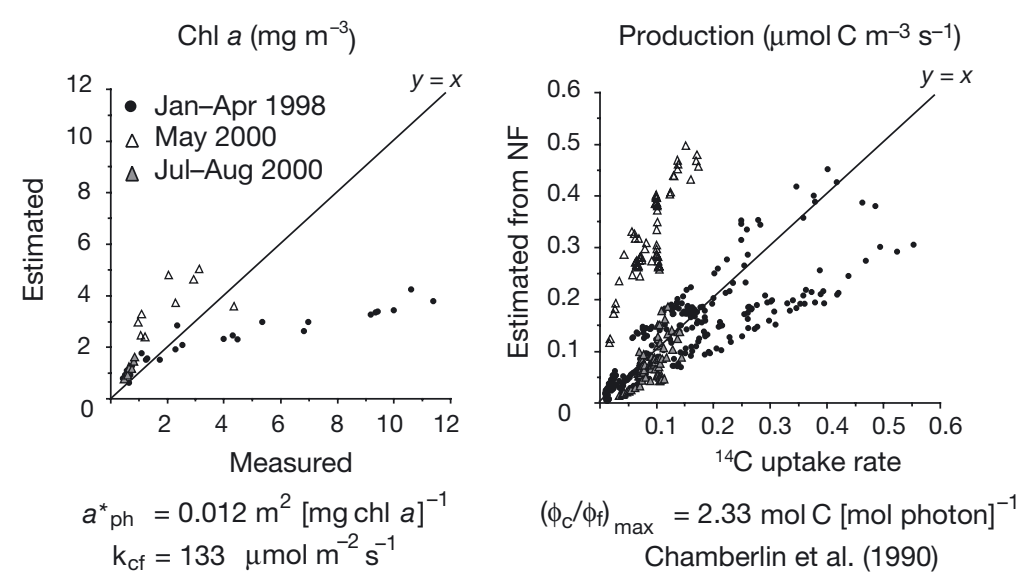

Fig. 2. Comparison of measured chl a (left) and primary production (right) versus estimates from natural fluorescence using the values of the biooptical parameters in Chamberlin et al. (1990). $a^{*}{ }_{\mathrm{ph}}$ : chl a specific absorption coefficient; $\left(\phi_{\mathrm{C}} / \phi_{\mathrm{f}}\right)_{\max }$ : maximum quantum yield ratio of photosynthesis to fluorescence; $\mathrm{k}_{\mathrm{cf}}$ : light saturation index
Late spring and summer

Water temperature was gradually warmed from 9 to $22^{\circ} \mathrm{C}$, and strong thermal stratification gradually developed. The thermocline extended to below $7.5 \mathrm{~m}$. Chl a ranged from 0.5 to $2.0 \mathrm{mg} \mathrm{m}^{-3}$, and diatoms and chlorophytes were the dominant group. Nitrate was consistently low, within $<1$ to $2 \mu \mathrm{M}$.

\section{Estimations using the equations of Chamberlin et al. (1990)}

Results using the equations of Chamberlin et al. (1990) are shown in Fig. 2 as a baseline for estimations of chl $a$ and the primary production. Chl a was overestimated at low concentrations and underestimated at the high 
concentrations. This indicated a non-linear relationship between chl $a$ and the ratio of $F_{\mathrm{f}}$ to PAR. As for the primary production, the correlation between measured and estimated values was not so good, and was highly overestimated for the data set during May 2000. This indicated that there were intra- and inter-seasonal variations in the bio-optical parameters, probably due to changes in the environmental conditions or species composition. The coefficient of determination is 0.24 for the data of all seasons $(\mathrm{n}=442) ; 76 \%$ of variation in primary production could not be explained by their equations.

\section{Estimation of chl a}

Winter to early spring

In Eq. (2), $\left(\mathrm{k}_{\mathrm{PAR}}+a_{\mathrm{chl}}\right)$ showed a significant positive relationship with chl a ( $p<0.05$, Fig. $3 a$, see Table 2 for values of the parameters).

$$
\mathrm{k}_{\mathrm{PAR}}+\mathrm{a}_{\mathrm{chl}}=0.59+0.011 \mathrm{chl} \mathrm{a}
$$
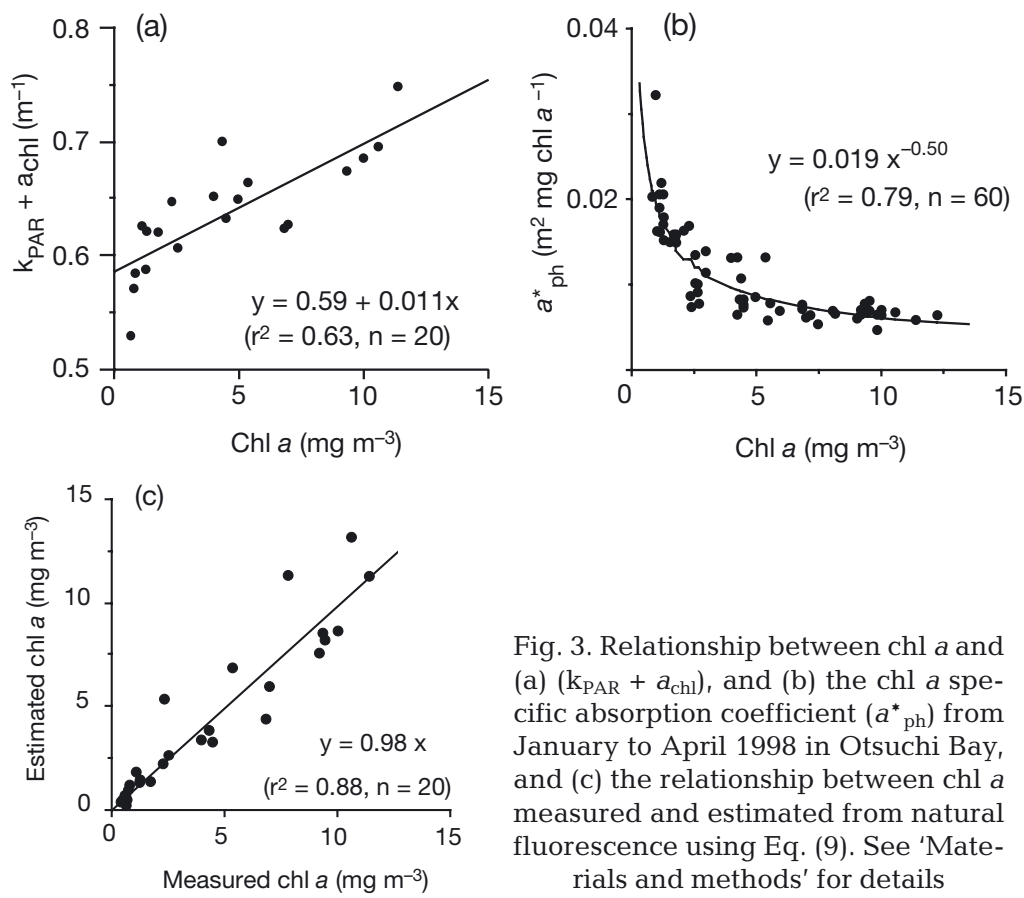

Fig. 3. Relationship between chl $a$ and (a) $\left(\mathrm{k}_{\mathrm{PAR}}+a_{\mathrm{chl}}\right)$, and (b) the chl a specific absorption coefficient $\left(a^{*}{ }_{p h}\right)$ from January to April 1998 in Otsuchi Bay, and (c) the relationship between chl $a$ measured and estimated from natural fluorescence using Eq. (9). See 'Materials and methods' for details
The chl a specific absorption coefficient, $a^{*}{ }^{*}$, showed wide variations from 0.005 to $0.032 \mathrm{~m}^{2}$ (mg chl $a)^{-1}$. This variation in $a^{*}$ ph was correlated with chl $a$, and can be expressed as a multiplicative function of chl a (p<0.05, Fig. 3b).

$$
a^{*} \text { ph }=0.019 \mathrm{chl} a^{-0.50}
$$

The quantum yield of fluorescence, $\phi_{\mathrm{f}}$, ranged within 0.02 and 0.04 . From the linear regression analysis it was determined that $\phi_{\mathrm{f}}$ was independent of chl $a$ and

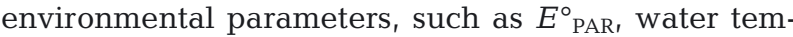
perature, nitrate concentration and light history $\left(\Sigma_{1-3} E_{\text {PAR, }}^{\circ}\right.$ daily $E_{\text {PAR }}^{\circ}$ at $7.5 \mathrm{~m}$ averaged for past $3 \mathrm{~d}$ ). By substituting Eqs. (7), (8) and the average of $\phi_{\mathrm{f}}$ (0.028) into Eq. (1) and rearranging, we obtained:

$$
\begin{aligned}
& 4 \pi(0.59+0.11 \mathrm{chl} \mathrm{a}) L_{\mathrm{u} \mathrm{chl}}- \\
& 0.00053 E^{\circ}{ }_{\text {PAR }} \operatorname{chl} a^{0.50}=0
\end{aligned}
$$

We solved Eq. (9) for chl a as a variable from the values of $L_{\mathrm{u} \text { chl }}$ and $E_{\text {PAR }}^{\circ}$ by applying the Newton approximation method (see Appendix 1). The chl a estimated from natural fluorescence was in good agreement with

\begin{tabular}{|c|c|c|c|c|c|}
\hline Date & $\begin{array}{l}\mathrm{k}_{\mathrm{PAR}}+a_{\mathrm{chl}} \\
\quad\left(\mathrm{m}^{-1}\right)\end{array}$ & $\begin{array}{c}\phi_{\mathrm{f}} \\
\left(\mathrm{mol}[\mathrm{mol}]^{-1}\right)\end{array}$ & $\begin{array}{c}a^{*} \mathrm{ph} \\
\left(\mathrm{m}^{2}[\mathrm{mg} \mathrm{chl} a]^{-1}\right)\end{array}$ & $\begin{array}{c}\left(\phi_{\mathrm{c}} / \phi_{\mathrm{f}}\right)_{\max } \\
\left(\mathrm{mol} \mathrm{C}[\mathrm{mol} \text { photon }]^{-1}\right)\end{array}$ & $\begin{array}{c}\mathrm{k}_{\mathrm{cf}} \\
\left(\mu \mathrm{mol} \mathrm{m} \mathrm{m}^{-2} \mathrm{~s}^{-1}\right)\end{array}$ \\
\hline \multicolumn{6}{|l|}{ Otsuchi Bay } \\
\hline $\begin{array}{l}\text { January to April } 1998 \\
\text { (n = 18) }\end{array}$ & $0.59+0.011 \mathrm{chl} \mathrm{a}$ & $0.028( \pm 0.006)$ & $0.019 \mathrm{chl} a^{-0.50}$ & $0.84+0.136 \mathrm{chl} a$ & $232( \pm 52)$ \\
\hline $\begin{array}{l}\text { May } 2000 \\
(\mathrm{n}=5)\end{array}$ & No data & $0.033+0.0064 \mathrm{chl} a$ & $0.027 \mathrm{chl} a^{-0.71}$ & $\begin{array}{c}-0.39+0.228 \mathrm{chl} a \\
+0.055 T\end{array}$ & $\begin{array}{c}-156+27.6 T \\
+10.7 \Sigma_{1-3} E_{\mathrm{PAR}}^{\circ}\end{array}$ \\
\hline July to August $2000(\mathrm{n}=7)$ & No data & $-0.001+0.046 \mathrm{chl} a$ & $0.016 \mathrm{chl} a^{-0.85}$ & & \\
\hline All $(n=30)$ & $0.59+0.011 \mathrm{chl} a$ & $0.031( \pm 0.007)$ & $0.019 \mathrm{chl} a^{-0.36}$ & $0.64+0.160 \mathrm{chl} a$ & $\begin{array}{l}-12.9+21.4 T \\
+7.95 \Sigma_{1-3} E_{\mathrm{PAR}}^{\circ}\end{array}$ \\
\hline \multicolumn{6}{|l|}{ Open sea } \\
\hline Sea of Japan $(n=5)$ & No data & $0.025( \pm 0.011)$ & $0.027( \pm 0.007)$ & $0.85( \pm 0.71)$ & $253( \pm 118)$ \\
\hline Sagami Bay (n = 3) & No data & $0.028( \pm 0.004)$ & $0.015( \pm 0.001)$ & $0.74( \pm 0.25)$ & $245( \pm 84)$ \\
\hline
\end{tabular}

Table 2. Seasonal and spatial variations in the bio-optical parameters (mean \pm SD) or their relationships with environmental factors (chl $a$, temperature, light history). Chl a: $\mathrm{mg} \mathrm{m}^{-3}$, $\mathrm{T}$ : temperature $\left({ }^{\circ} \mathrm{C}\right), \Sigma_{1-3} E_{\text {PAR }}^{\circ}$ daily $E_{\text {PAR }}^{\circ}$ at $7.5 \mathrm{~m}$ averaged for over $3 \mathrm{~d}$ $\left(\mathrm{mol} \mathrm{m}^{-2} \mathrm{~d}^{-1}\right)$. See Table 1 for all other definitions 
that measured by water sampling (Fig. 3C). The correlation coefficient for the multiple regression is 0.88 and the slope is 0.98 .
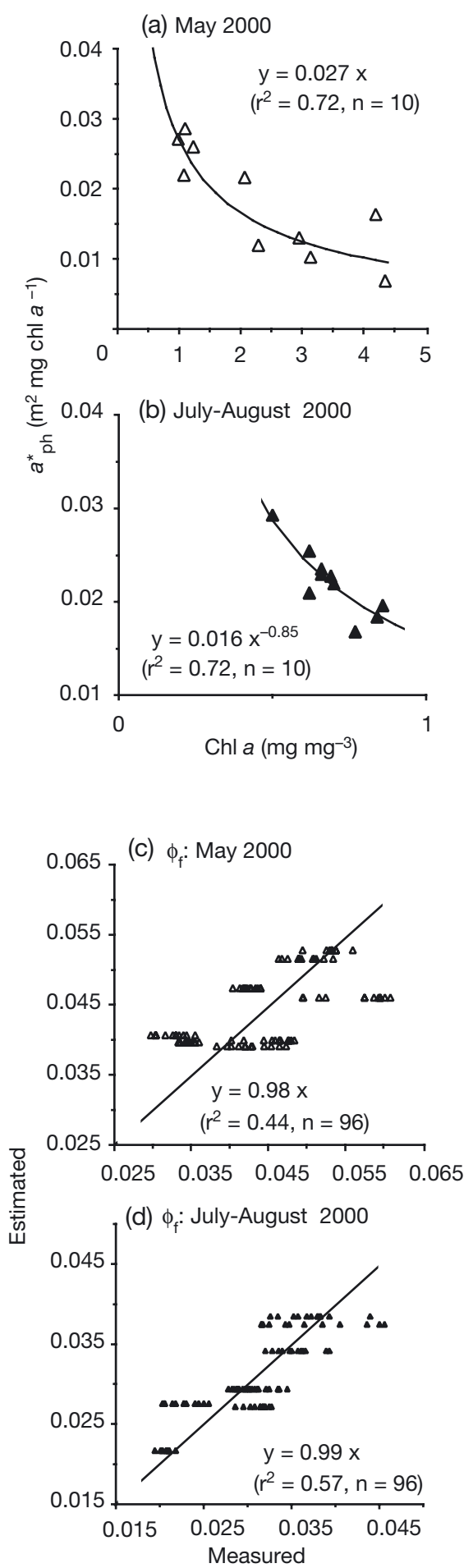

Fig. 4. Relationship between chl $a$ and $a^{*}$ ph during (a) May 2000 and (b) July to August 2000. Comparison of $\phi_{\mathrm{f}}$ measured and estimated during (c) May 2000 and (d) July to August 2000 in Otsuchi Bay. See 'Materials and methods' for details
Late spring and summer

$a^{*}{ }_{p h}$ could also be expressed as a multiplicative function of chl a during these periods ( $p<0.05$, Fig. $4 a, b$ ). However, the relationship varied seasonally:

$$
\begin{gathered}
\text { Late spring: } a^{*}{ }_{\mathrm{ph}}=0.027 \mathrm{chl} a^{-0.71} \\
\text { Summer: } a^{*}{ }_{\mathrm{ph}}=0.016 \mathrm{chl} a^{-0.85}
\end{gathered}
$$

$\phi_{\mathrm{f}}$ ranged by factors of 2 and showed significant linear relationships with chl a during each period $(\mathrm{p}<0.05$, Fig. 4c,d).

$$
\begin{aligned}
& \text { Late spring: } \phi_{\mathrm{f}}=0.033+0.0064 \mathrm{chl} a \\
& \text { Summer: } \phi_{\mathrm{f}}=-0.001+0.046 \mathrm{chl} a
\end{aligned}
$$

By applying the above relationships for each period, Eq. (1) became:

Late spring:

$$
\begin{gathered}
4 \pi(0.59+0.011 \mathrm{chl} \mathrm{a}) L_{\mathrm{u} \mathrm{chl}}- \\
0.027(0.033+0.0064 \mathrm{chl} \mathrm{a}) E^{\circ}{ }_{\mathrm{PAR}} \mathrm{chl} a^{0.29}=0
\end{gathered}
$$

Summer:

$$
\begin{gathered}
4 \pi(0.59+0.011 \mathrm{chl} \mathrm{a}) L_{\mathrm{u} \mathrm{chl}}- \\
0.016\left(-0.001+0.046 \mathrm{chl} \text { a) } E_{\mathrm{PAR}}^{\circ} \operatorname{chl} a^{0.15}=0\right.
\end{gathered}
$$

Chl a was estimated from the values of $L_{\mathrm{u}} \mathrm{chl}$ and $E_{\text {PAR }}^{\circ}$ and showed good agreement with the measured values for each period (Fig. 5). The correlation coefficients for the multiplicative regressions are 0.78 during

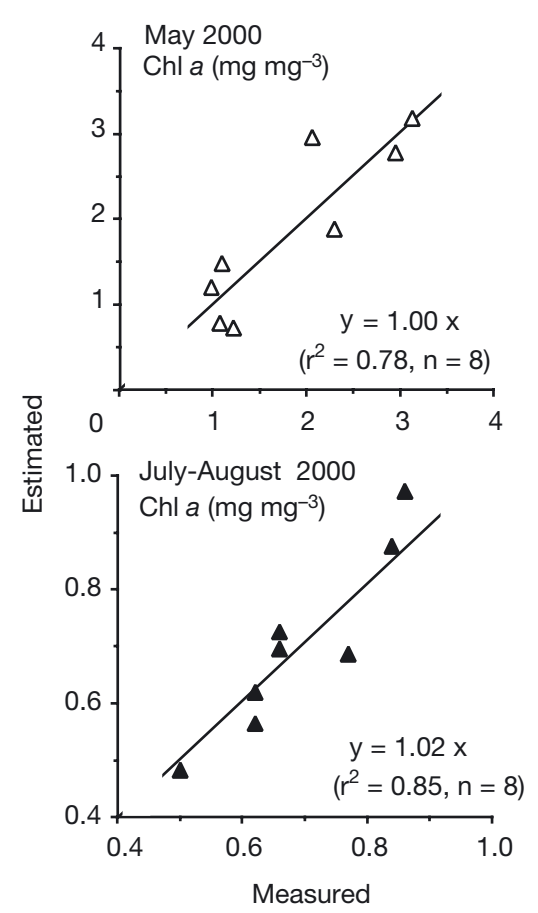

Fig. 5. Comparison of measured chl a versus estimates from natural fluorescence during May 2000 (upper panel) and from July to August 2000 (lower panel) 
May and 0.85 during July to August, and the slopes are 1.00 and 1.02, respectively.

\section{Estimation of primary production}

Winter to early spring

Since no significant relationships were observed between $\phi_{\mathrm{f}}$ and $E_{\mathrm{PAR}}^{\circ}\left(\phi_{\mathrm{C}} / \phi_{\mathrm{f}}\right)_{\max }$ and $\mathrm{k}_{\mathrm{Cf}}$ were obtained from $\phi_{\mathrm{f}}$ and the $P$-E curve parameters, $\phi_{\mathrm{c}} \max$ and $E_{\mathrm{k}}$ for each measurement. $\left(\phi_{\mathrm{C}} / \phi_{\mathrm{f}}\right)_{\max }$ and $\mathrm{k}_{\mathrm{cf}}$ ranged widely, from 0.7 to 2.6 (mean 2.1) mol C (mol photon) ${ }^{-1}$, and 146 to 350 (270) $\mu \mathrm{mol} \mathrm{m} \mathrm{m}^{-2} \mathrm{~s}^{-1}$, respectively. The causes of the variations in $\left(\phi_{\mathrm{c}} / \phi_{\mathrm{f}}\right)_{\max }$ and $\mathrm{k}_{\mathrm{cf}}$ were examined by multiple regression analysis in which chl $a, E_{\text {PAR }}^{\circ}$ water temperature, nitrate concentration and light history were used as independent variables. As a result, $\left(\phi_{\mathrm{c}} / \phi_{\mathrm{f}}\right)_{\max }$ showed a significant positive relationship with chl a ( $\mathrm{p}<0.05$, Fig. 6, left-hand panel).

$$
\left(\phi_{\mathrm{C}} / \phi_{\mathrm{f}}\right)_{\max }=0.84+0.136 \mathrm{chl} \mathrm{a}
$$

As $k_{\mathrm{cf}}$ was independent from any of the variables, its average of $270 \mu \mathrm{mol} \mathrm{m} \mathrm{m}^{-2} \mathrm{~s}^{-1}$ was used as the constant. The estimated primary production from $E_{\text {PAR }}^{\circ}$ and $F_{\mathrm{f}}$ with the above equation and constant showed good agreement with the measured primary production rate (Fig. 6, right-hand panel). The correlation coefficient for the multiple regression is 0.85 and the slope is 0.95 .

\section{Late spring and summer}

As the number of data points for each season was not sufficient for regression analysis, all the data were

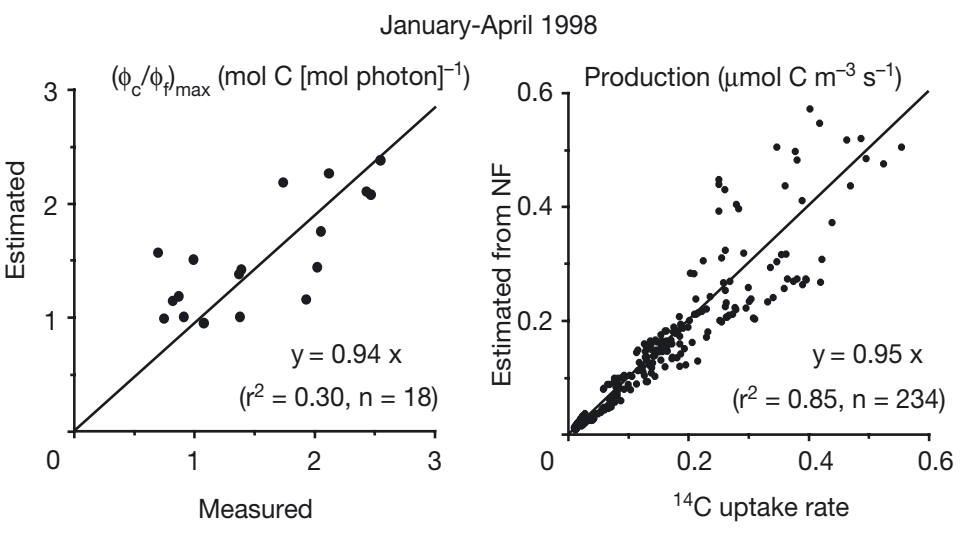

Fig. 6. Comparison of measured versus estimated $\left(\phi_{\mathrm{c}} / \phi_{\mathrm{f}}\right)_{\max }$ (left-hand panel; see 'Materials and methods' for details), and primary production measured by ${ }^{14} \mathrm{C}$ uptake versus estimates from natural fluorescence (right-hand panel) from January to April 1998

pooled and treated together. $\left(\phi_{\mathrm{C}} / \phi_{\mathrm{f}}\right)_{\max }$ ranged from 0.28 to $1.18 \mathrm{~mol} \mathrm{C}$ (mol photon) ${ }^{-1}$ and showed significant relationships with chl $a$ and water temperature, $T\left({ }^{\circ} \mathrm{C}\right)(\mathrm{p}<0.05$, Fig. 7a).

$$
\left(\phi_{\mathrm{C}} / \phi_{\mathrm{f}}\right)_{\max }=-0.39+0.228 \mathrm{chl} \mathrm{a}+0.055 T
$$

$\mathrm{k}_{\mathrm{cf}}$ markedly fluctuated from 175 to $680 \mu \mathrm{mol} \mathrm{m} \mathrm{m}^{-2} \mathrm{~s}^{-1}$ and showed significant correlation with water temperature and light history, $\Sigma_{1-3} E_{\text {PAR }}^{\circ}\left(\mathrm{mol} \mathrm{m} \mathrm{m}^{-2} \mathrm{~d}^{-1}\right)$, and daily $E_{\text {PAR }}^{\circ}$ at $7.5 \mathrm{~m}$ averaged over the past $3 \mathrm{~d}$ (p< 0.05, Fig. 7b).

$$
\mathrm{k}_{\mathrm{cf}}=-156+27.6 T+10.7 \Sigma_{1-3} E^{\circ} \mathrm{PAR}
$$

The estimated primary production from $E^{\circ}{ }_{\text {PAR }}$ and $F_{\mathrm{f}}$ with the above equation and constant showed good agreement with the measured primary production rate (Fig. 7c). The correlation coefficient for the multiple regression is 0.61 and the slope is 0.95 .
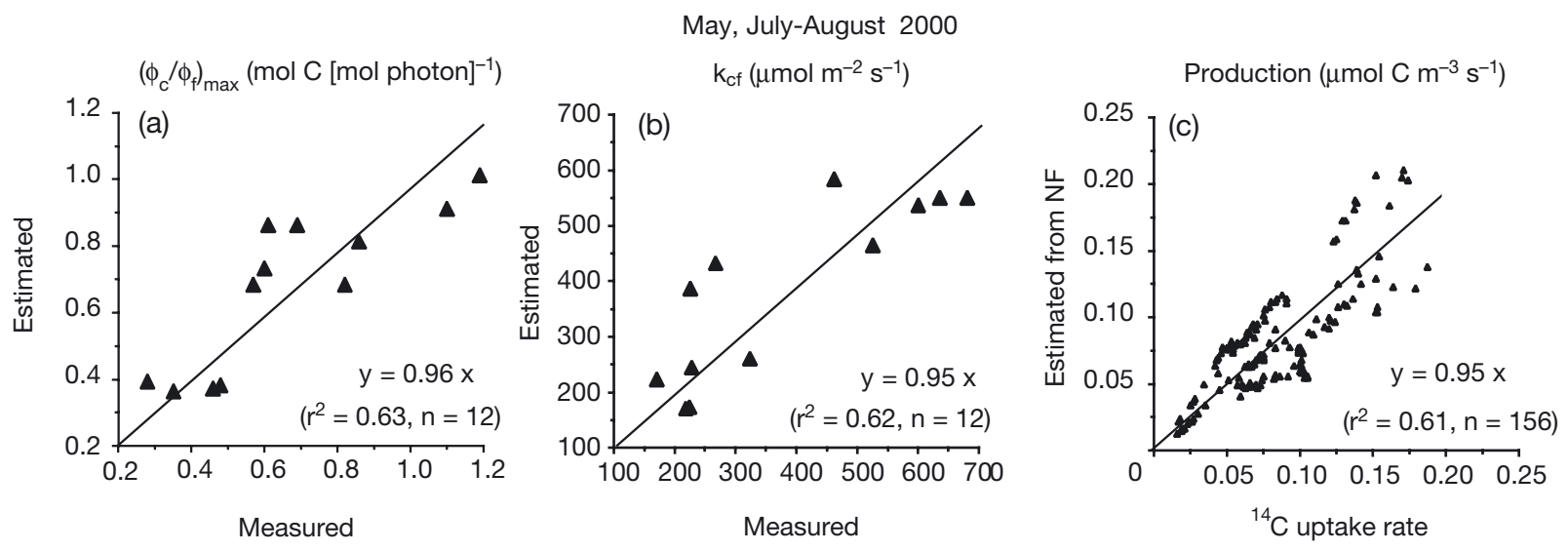

Fig. 7. Comparison of measured versus estimated (a) $\left(\phi_{\mathrm{c}} / \phi_{\mathrm{f}}\right)_{\max }$ and (b) $\mathrm{k}_{\mathrm{cf}}$ during May, and from July to August 2000. (c) Comparison of production measured by ${ }^{14} \mathrm{C}$ uptake versus estimates from natural fluorescence. See 'Materials and methods' for details 
Chl a $\left(\mathrm{mg} \mathrm{m}^{-3}\right)$
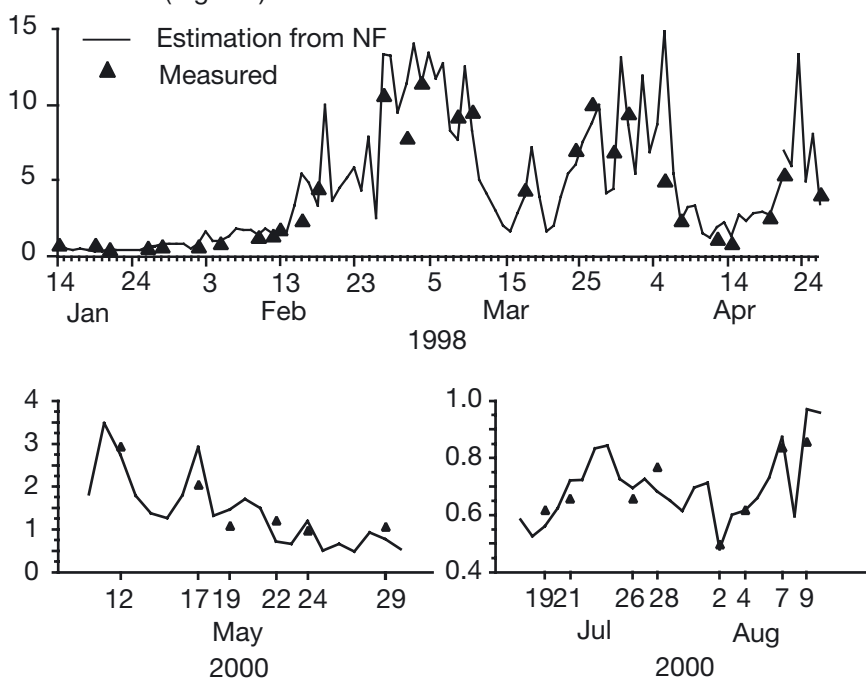

Fig. 8. Daily variations in chl a estimated from natural fluorescence from January to April 1998 (upper panel), and during May and from July to August 2000 (lower panels). Closed triangles represent the values obtained from water sampling

\section{Daily changes in chl $a$ and primary production}

By applying the relationships of $a^{*}{ }_{p h},\left(\phi_{\mathrm{c}} / \phi_{\mathrm{f}}\right)_{\max }$ and $\mathrm{k}_{\mathrm{cf}}$ with chl $a$, water temperature and light history, accuracy of production estimation is much improved from the result using the equations of Chamberlin et al. (1990); the coefficient of determination is 0.85 for the data of all seasons $(\mathrm{n}=442)$. Daily records of $\mathrm{chl}$ $a$ and primary production from the natural fluorescence sensor are shown in Figs. 8 \& 9. The estimation of both chl $a$ and primary production from natural fluorescence were consistently in good agreement with those measured over wide ranges for each observation period. The results of natural fluorescence revealed several peaks of chl $a$ and primary production within a few days, which were not observed by the water sampling, carried out twice a week.

\section{DISCUSSION}

\section{Variation in the bio-optical parameters}

The variation in $\left(\mathrm{k}_{\mathrm{PAR}}+a_{\mathrm{chl}}\right)$ was mainly controlled by phytopankton abundance. Their linear dependency on chl a was also modeled by Kiefer et al. (1989), who stated that the sum $\mathrm{k}_{\mathrm{PAR}}+a_{\text {chl }}$ changes little at low chl a levels of $<2 \mathrm{mg} \mathrm{m}^{-3}$. The effect of detritus and yellow substances on their variations seemed to be small in
Otsuchi Bay as well as the large part of the open ocean (Case I waters). However, the optical properties of most coastal waters are affected by the suspended inorganic sedimentary material or biogenic particulate (Case II waters). Investigation and monitoring of their optical properties are now common needs in the biooptical measurements of the primary production for coastal waters.

By applying the relationship between $a^{*}$ ph and chl $a_{\text {, }}$ chl a estimated from natural fluorescence was in good agreement with the measured chl a. Covariances between $\mathrm{a}^{*}$ ph and chl $a$, similar to those found in the present study, have been widely reported from various natural phytoplankton assemblages (e.g. Mitchell \& Kiefer 1988, Bricaud et. al. 1995). However, in previous studies on the natural fluorescence method, $a^{*}{ }_{p h}$ was treated as a constant. In these studies, chl a was generally low $\left(<2 \mathrm{mg} \mathrm{m}^{-3}\right)$ in the target area and $a^{*}{ }_{\mathrm{ph}}$ values varied widely within a narrow range of chl a. As a result, the exponential relationships between $a^{*}{ }_{p h}$ and chl $a$ were obscured. The dependence of $a^{*}$ ph on chl $a$ has been mainly attributed to 2 factors: (1) the level of the package effect; i.e. pigments packed into large or densely packed chloroplasts are less efficient at absorbing light than those which are smaller and dispersed (Kirk 1994), and (2) the differential contribution of accessory pigments to light absorption (Bidigare et al. 1990, Hoepffner \& Sathyendranath 1991). As a result of pigment analysis, the ratio of accessory pigments to chl a did not show a significant change with

Production (mg C m $\left.\mathrm{m}^{3} \mathrm{~d}^{-1}\right)$
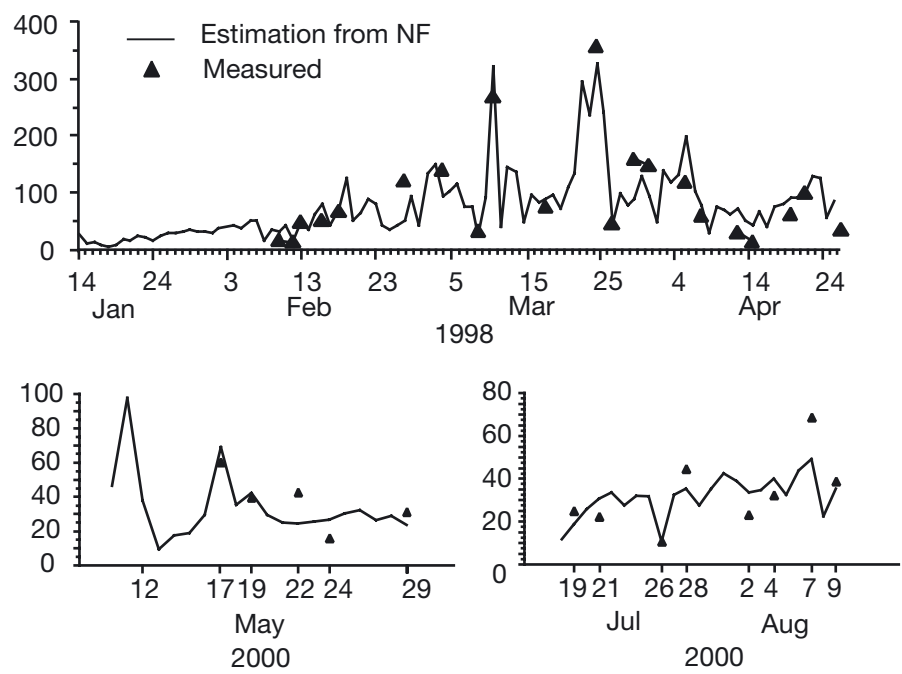

Fig. 9. Daily variations in primary production estimated from natural fluorescence from January to April 1998 (upper panel), and during May and from July to August 2000 (lower panels). Closed triangles represent the values obtained from water sampling 
(a)

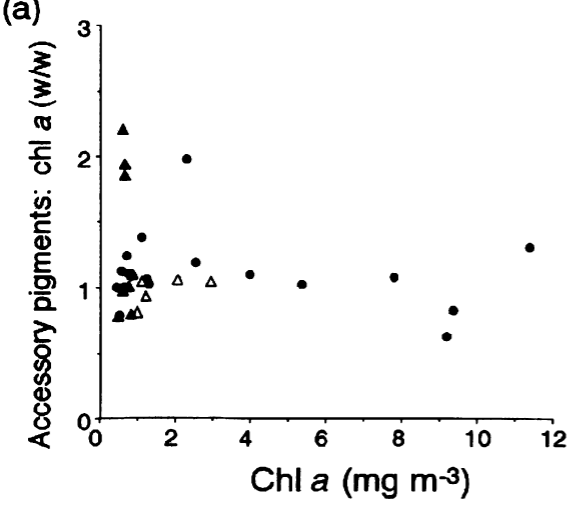

(c)

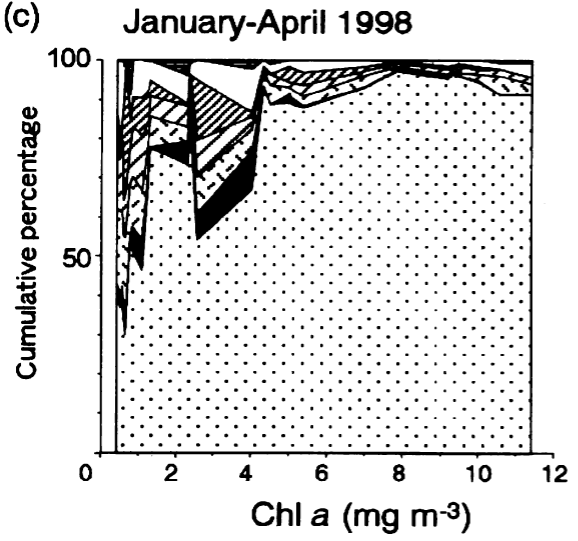

(b)

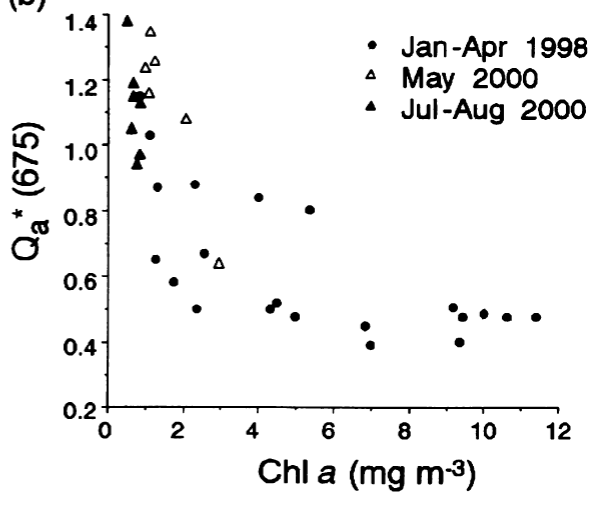

May, July-August 2000

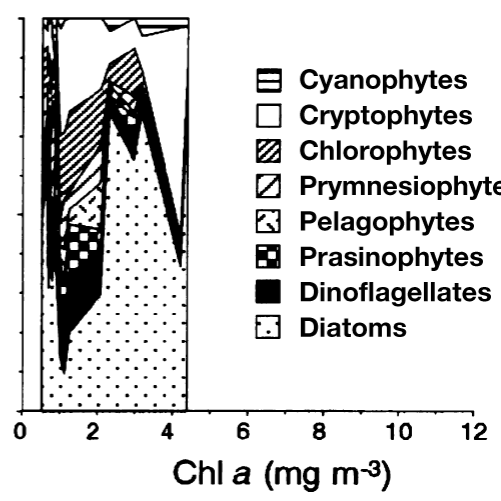

Fig. 10. Relationship of chl a with (a) the ratio of accessory pigments to chl $a$ and (b) the package effect index at $675 \mathrm{~nm}\left[Q^{*}{ }_{a}(675)\right.$; see 'Discussion'], and the class-level taxonomical composition of phytoplankton (c) from January to April 1998 and (d) during May 2000, and from July to August 2000 in Otsuchi Bay chl a (Fig. 10a). In order to quantify the package effect, the package effect index (Morel \& Bricaud 1981) at a wave length of $675 \mathrm{~nm}, Q^{*}{ }_{a}(675)$, was calculated, because the influence of accessory pigments is minimal at $675 \mathrm{~nm}$ :

$$
Q^{*}{ }_{a}(675)=a^{*}{ }_{\mathrm{ph}}(675) / a^{*}{ }_{\text {sol }}(675)
$$

where $a^{*}{ }_{\text {sol }}(675)$ is the specific absorption coefficient at $675 \mathrm{~nm}$ of the same cellular matter, ideally dispersed in a dissolved state and taken as $0.0206 \mathrm{~m}^{2}(\mathrm{mg} \mathrm{chl} \mathrm{a})^{-1}$. Over the range of chl $a_{1}$ the values of $Q^{*}{ }_{a}(675)$ decreased from around the theoretical maximum value of 1 (no package effect) to 0.4 , as chl a increased (Fig. 10b). Some values of low chl a exceeded the theoretical upper limit of 1 , which may be partly due to the uncertainty in the path-length amplification factor; that is, the difference in the optical densities between the suspended state and on the filter. However, based on the pigment analysis, the percentage contribution of diatoms, known to have a high package effect due to their large cell size, markedly increased with chl a (Fig. 10c). These results indicated that the increase in the ratio of diatoms and the package effect with chl $a$ was a main cause of the covariance between $a^{*}{ }_{p h}$ and chl a.

The variation in $\phi_{\mathrm{f}}$ was associated with chl a during late spring and summer; however, there were scat- tered data points and the correlation coefficients were low. This unexplained variance may be due to other environmental factors. $\phi_{\mathrm{f}}$ has been known to change primarily with light intensity, owing to the photochemical and non-photochemical (heat loss) quenching of fluorescence (Schreiber et al. 1986). However, in the present study, there was no significant relationship with $\phi_{\mathrm{f}}$, and application of its relationship with chl a adequately improved the accuracy of chl a estimation.

$\left(\phi_{\mathrm{c}} / \phi_{\mathrm{f}}\right)_{\max }$ fluctuated seasonally from around the upper $(<5)$ to the lower $(0.2)$ limit of previous studies (e.g. Chamberlin et al. 1990, Garcia-Mendoza \& Maske 1996). The temporal fluctuation in $\left(\phi_{\mathrm{C}} / \phi_{\mathrm{f}}\right)_{\max }$ was associated with chl $a$ in the winter to spring, and with chl a and water temperature in the summer. This is the first report of the relationship between chl $a$ and $\left(\phi_{\mathrm{c}} / \phi_{\mathrm{f}}\right)_{\max }$. Temperature (Chamberlin \& Marra 1992) and nutrients (Lizotte \& Priscu 1994) have been reported as factors regulating $\left(\phi_{\mathrm{c}} / \phi_{\mathrm{f}}\right)_{\max }$. The variability in $\left(\phi_{\mathrm{c}} / \phi_{\mathrm{f}}\right)_{\max }$ was mainly due to changes in $\phi_{\mathrm{cmax}}$, and not in $\phi_{\mathrm{f}}$, as previous studies have suggested (eg. Chamberlin et al. 1990). In the ocean, $\phi_{\text {cmax }}$ has been known to change from $<0.01$ to -0.10 with nutrient conditions, light intensity, species composition and so on (e.g. Côte \& Platt 1983, Cleveland et al. 1989, Babin et al. 1996). The relationship between chl $a$ and the quantum yield ratio may 
be due to changes in taxonomical composition, as observed in $a^{*}$ ph in the present study and reported in $\phi_{\mathrm{cmax}}$ for coastal phytoplankton during spring and summer (Côte \& Platt 1983). A temperature dependence of $\phi_{\mathrm{c} \max }$ has been reported from the Antarctic Ocean by Tilzer et al. (1985), and from the California Current System by Sosik (1996). Although $\phi_{\mathrm{cmax}}$ was formerly thought to be free of the influences of temperature because they were not directly related to enzymatic activity (Talling 1957), recently, its dependence on temperature has been explained by temperature regulation on the fluidity of membranes of and between LHCs and photochemical reaction centers (Fork 1976, Prézelin et al. 1991).

$\mathrm{k}_{\mathrm{cf}}$ showed a marked seasonal change from late spring to summer. Thermal stratification accelerated the rise in water temperature and light intensity at the mooring depth and became the cause of temporal fluctuations in $\mathrm{k}_{\mathrm{cf}}$ during the late spring and summer. The temperature dependency of the $P-E$ parameter $E_{\mathrm{k}}$, which was equivalent to $\mathrm{k}_{\mathrm{cf}}$, may be explained by a change in membrane fluidity, as noted above (Fork 1976, Prézelin et al. 1991). A light dependency of $E_{\mathrm{k}}$ has been reported in several studies (Côte \& Platt 1984). While no seasonal variation of $E_{\mathrm{k}}$ has been observed in some studies (e.g. Shaw \& Purdie 2001), it has been proposed that high water turbidity and short vertical mixing prevent phytoplankton from photoadaptation or photoacclimation to a level of PAR (Uncles \& Joint 1982).

Diurnal changes of the parameter were not investigated here. Because most attention was paid to seasonal change, every water sample was collected at the same time (08:00 to 10:00 h) in the morning, and diurnal changes were unresolved. There have been few studies on the diel cycle of $\phi_{\mathrm{c} \max }$ or $\phi_{\mathrm{f}}$. Stegmann et al. (1992) reported that $\left(\phi_{\mathrm{c}} / \phi_{\mathrm{f}}\right)_{\max }$ changed diurnally by a factor of 2, and was low in the evening compared to the morning and noon in the surface water of the equator-

Table 3. Total primary production from continuous record of natural fluorescence during each period, and coefficient of variation $(\mathrm{CV})$ when calculated at 3 , 7 and 14 d intervals

\begin{tabular}{|lcccc|}
\hline Date (dd/mm/yy) & $\begin{array}{c}\text { Primary } \\
\text { production } \\
\left(\mathrm{mg} \mathrm{C} \mathrm{m}^{-3}\right)\end{array}$ & $\begin{array}{c}\text { CV for 3 d } \\
\text { interval } \\
(\%)\end{array}$ & $\begin{array}{c}\text { CV for 7 d } \\
\text { interval } \\
(\%)\end{array}$ & $\begin{array}{c}\text { CV for 14 d } \\
\text { interval } \\
(\%)\end{array}$ \\
\hline $\begin{array}{l}\text { 14/01/98-28/02/98 (46 d) } \\
01 / 03 / 98-26 / 04 / 98\end{array}$ & 1207 & 40 & 25 & 43 \\
$(57 \mathrm{~d})$ & 5393 & 18 & 23 & 32 \\
$\begin{array}{l}\text { (20/04/00-29/05/00 } \\
(40 \mathrm{~d})\end{array}$ & 984 & 22 & 31 & 36 \\
$\begin{array}{l}1807 / 00-09 / 08 / 00 \\
(23 \mathrm{~d})\end{array}$ & 729 & 9 & 18 & 18 \\
Average & - & 22 & 24 & 32 \\
\hline
\end{tabular}

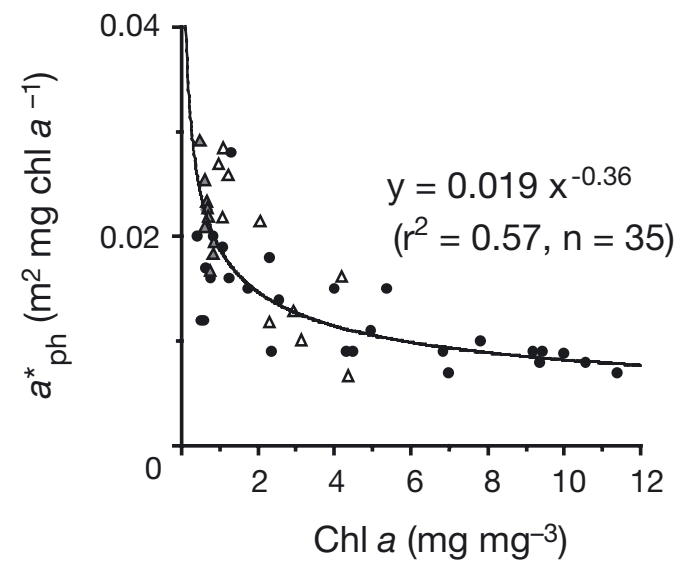

- Jan-Apr $1998 \Delta$ May 2000 s Jul-Aug 2000

Fig. 11. Relationship between chl a and chl a specific absorption coefficient $\left(a^{*}{ }_{\mathrm{ph}}\right)$ for the data of all seasons in Otsuchi Bay

ial Pacific. From early studies carried out in the ocean, it is clear that $\phi_{\mathrm{f}}$ is lower in the surface ocean during the day than at night (Owens et al. 1980, Abbott et al. 1982). Babin et al. (1995) reported a diel cycle of $\phi_{c \max }$ with a maximum at around noon in a coastal area. They also suggested that the diurnal variations accounted for the large part of the $\phi_{\text {cmax }}$ variations. Thus, the diurnal variations in the bio-optical parameters may not be a negligible problem for the precise estimation of the photosynthetic rate by the natural fluorescence method.

\section{Application of natural fluorescence methods for various seasons and areas}

To evaluate possible errors in the estimation of primary production by intermittent water sampling, primary production was calculated at 3,7 and $14 \mathrm{~d}$ intervals (Table 3 ). The average coefficients of variation $(\mathrm{CV})$ for the 3,7 and 14 d intervals were 22,24 , and 32 , respectively, increasing slightly as the number of interval days increased. From this result we can say that there is an uncertainty of ca. 20 to $30 \%$ for 3 to $14 \mathrm{~d}$ intervals between observations in the estimation of primary production.

To estimate primary production from natural fluorescence with a seasonally common set of equations, the all-seasons data of $a^{*}{ }_{p h},\left(\phi_{\mathrm{c}} / \phi_{\mathrm{f}}\right)_{\max }$ and $\mathrm{k}_{\mathrm{cf}}$ were analyzed together. As a result, $a^{*}$ ph and $\left(\phi_{\mathrm{c}} / \phi_{\mathrm{f}}\right)_{\max }$ were associated with chl $a_{\text {, }}$ 


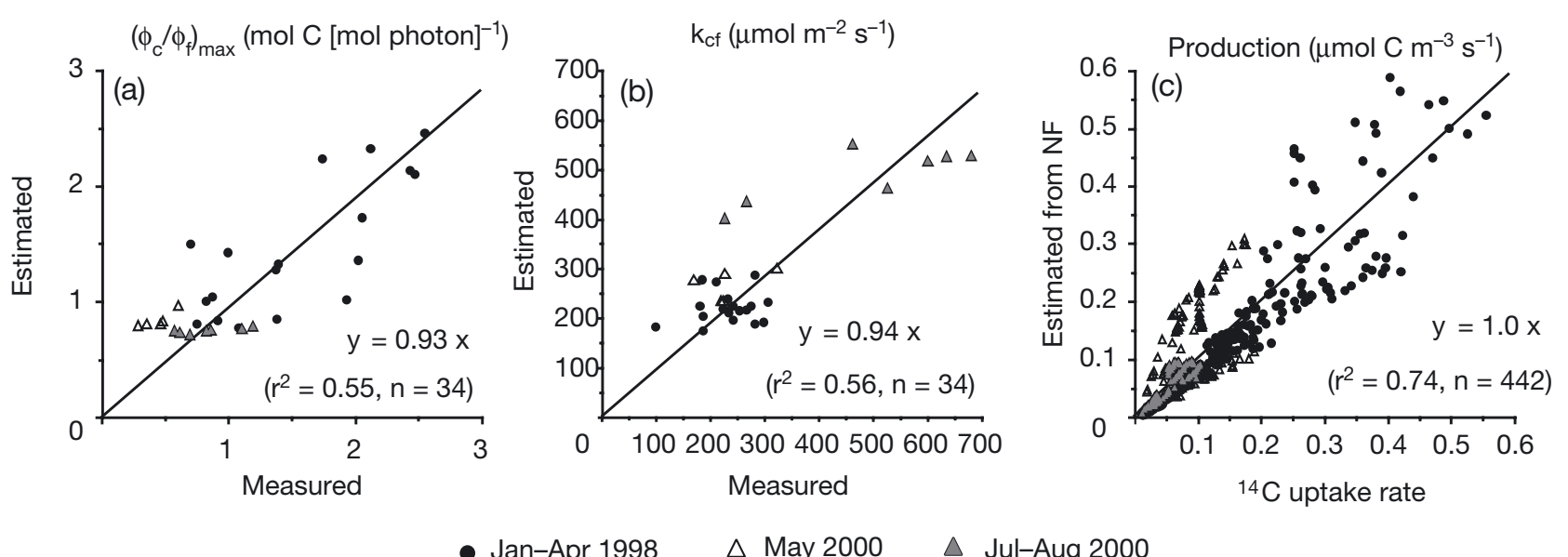

Fig. 12. Comparison of measured versus estimated (a) $\left(\phi_{\mathrm{c}} / \phi_{\mathrm{f}}\right)_{\max ,}$ (b) $\mathrm{k}_{\mathrm{cf}}$ and (c) primary production in Otsuchi Bay from the seasonally common algorithm. See 'Materials and methods' for details

and $\mathrm{k}_{\mathrm{cf}}$ was associated with temperature and light history (Figs. $11 \& 12 \mathrm{a}, \mathrm{b})$.

$$
\begin{aligned}
& a^{*}{ }_{\mathrm{ph}}=0.019 \mathrm{chl} a^{-0.36} \\
& \left(\phi_{\mathrm{c}} / \phi_{\mathrm{f}}\right)_{\max }=0.64+0.160 \mathrm{chl} a \\
& \mathrm{k}_{\mathrm{cf}}=12.9+21.4 T+7.95 \Sigma_{1-3} E^{\circ}{ }_{\mathrm{PAR}}
\end{aligned}
$$

According to the coefficients in these equations, it appeared that seasonal change in $\left(\phi_{\mathrm{c}} / \phi_{\mathrm{f}}\right)_{\max }$ was mainly due to the change in chl a associated with bloom formation during the early spring, and that the change in $\mathrm{k}_{\mathrm{cf}}$ was due to that during late spring and summer. These relationships also gave adequate estimations of the primary production rate (Fig. 12c), though the accuracy of estimation was worse compared with using the relationships sorted by season. Thus, we can use the natural fluorescence method with a seasonally common algorithm in Otsuchi Bay. Furthermore, we tested the applicability of this algorithm to other sites,
Sagami Bay (a bay opening into the Pacific Ocean) and the Sea of Japan. Buoy observations with a sensor and measurements of photosynthetic rate by incubation were conducted at a station during a 2 to $3 \mathrm{~d}$ period for each site. As a result, the estimated primary production showed good agreement with the measured value (Fig. 13c). However, the variation in $\left(\phi_{\mathrm{c}} / \phi_{\mathrm{f}}\right)_{\max }$ was not represented by estimation, and $\mathrm{k}_{\mathrm{cf}}$ was overestimated (Fig. 13a,b). In these waters, the seasonal change in the bio-optical parameters may differ from the change in Otsuchi Bay. In addition to this, in order to cover spatial variations in primary production, it is necessary to deploy multiple moorings at various points, which represent each characteristic region (cf. coast, transit and offshore; the upper and lower euphotic layer; within and below the mixed layer). For instance, $a^{*}{ }_{\mathrm{ph}}, \phi_{\mathrm{f}}$ and $\phi_{\mathrm{c} \max }$ change with depth, owing to light and nutrient conditions
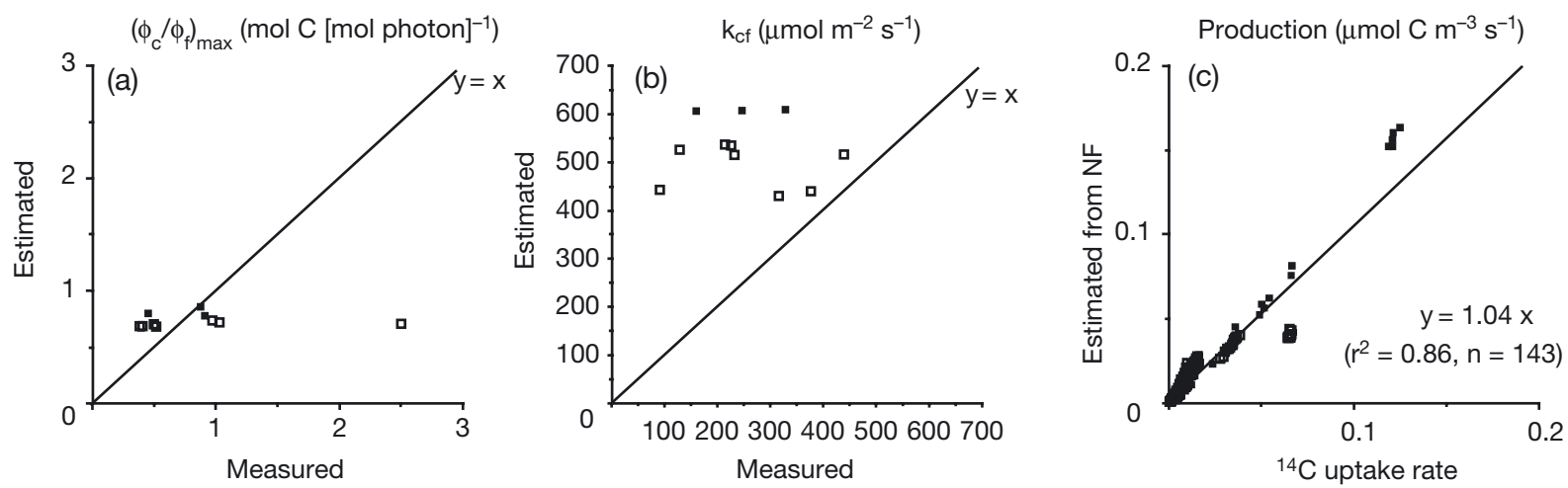

- Sea of Japan (Sep-Oct 1999) . Sagami Bay (Sep 2000)

Fig. 13. Comparison of measured versus estimated (a) $\left(\phi_{\mathrm{c}} / \phi_{\mathrm{f}}\right)_{\max }(\mathrm{b}) \mathrm{k}_{\mathrm{cf}}$ and (c) primary production in Sea of Japan and Sagami Bay from the seasonally common algorithm for Otsuchi Bay. See 'Materials and methods' for details 
(Cleveland et al. 1989, Lizotte \& Priscu 1994, Babin et al. 1996, etc.). A more extensive examination is needed for year-round applicability and to cover a wider area.

In conclusion, the present study revealed that the seasonal variation in $a^{*}{ }_{\mathrm{ph}},\left(\phi_{\mathrm{c}} / \phi_{\mathrm{f}}\right)_{\max }$ and $\mathrm{k}_{\mathrm{cf}}$ were related to $\mathrm{chl} a$, water temperature and light history in Otsuchi Bay. By applying these relationships, it was possible to monitor the primary production continuously from natural fluorescence by mooring the sensor in coastal water, where phytoplankton biomass and species composition markedly fluctuate with environmental conditions. As an alternative to natural fluorescence methods, active fluorescence methods, such as pulse amplitude modulation (PAM, Schreiber 1986) or the fast repetition rate (FRR) fluorescence method (Kolber \& Falkowski 1993), have been exploited. FRR sensors, which can be moored, are also now available (Chelsea Instruments). They can provide rapid assessment of several parameters in the photosynthetic processes, such as the quantum yield ratio of PSII $\left(\Delta \phi_{\max }\right)$, the effective absorption cross-section of PSII $\left(\sigma_{\text {PSII }}\right)$ and non-photochemical quenching. However, the published assessments of these methods, by comparing them with more standard ${ }^{14} \mathrm{C}$ methods, are insufficient at this stage (Suggett et al. 2001). Furthermore, they require more unknown parameters, such as the photosynthetic quotient (PQ) and $\mathrm{n}_{\mathrm{PSII}}$, which are known to fluctuate. Thus, it may be more difficult to evaluate the parameters in the active fluorescence method, due to its complexity in calculation, than those in the natural fluorescence method. Recently, several satellite sensors, such as MERIS (Doerffer et al. 1999), and MODIS (Joint \& Groom 2000), that are optimized for observations of coastal zones, have been working, and algorithms for those are now under development. These sensors have bands for measuring the solar-stimulated fluorescence of phytoplankton chlorophyll. The algorithm developed by the present study for Otsuchi Bay could be used for interpreting fluorescence signals from satellite remote sensing. In the future it is expected that the mooring arrays of natural fluorescence sensors may be used to calibrate such imagery, both in the horizontal and the vertical directions.

Acknowledgements. We are grateful to H. Otobe, K. Morita, S. Kaga, M. Takagi and the staff of the Otsuchi Marine Research Center for their co-operation at sea, and H. Ogawa for co-operation with the nutrient analyses. We also thank N. Ramaiah for her critical reading of the manuscript. Financial research support was provided from the Grant-in-aid (\#11205207, \#11660181), Creative Basic Research Funds (\#12NP0201) and the Project on Ocean Productivity Profiling System, Core Research for Evolutionary Science and Technology. T.Y. acknowledges the financial support by the ANESC, the University of Tokyo.

\section{LITERATURE CITED}

Abbott MR, Richerson PJ, Powell TM (1982) In situ response of phytoplankton fluorescence to rapid variations in light. Limnol Oceanogr 27:218-255

Babin M, Therriault JC, Legendre L, Nieke B, Reuter R, Condal A (1995) Relationship between the maximum quantum yield of chlorophyll $a$ in vivo fluorescence in the Gulf of St. Lawrence. Limnol Oceanogr 40:956-968

Babin M, Morel A, Claustre H, Bricaud A, Kolber Z, Falkowski PG (1996) Nitrogen- and irradiance-dependent variations of the maximum quantum yield of carbon fixation in eutrophic, mesotrophic and oligotrophic marine systems. Deep-Sea Res I 43:1241-1272

Behrenfeld MJ, Falkowski PG (1997) Photosynthetic rates derived from satellite-based chlorophyll concentration. Limnol Oceanogr 42:1-20

Bidigare RR, Ondrusek ME, Morrow JH, Kiefer DA (1990) In vivo absorption properties of algal pigments. Ocean Optics X, Proc. SPIE Int Soc Opt Eng, 1302: 290-302

Bricaud A, Babin M, Morel A, Claustre H (1995) Variability in the chlorophyll-specific absorption coefficients of natural phytoplankton: analysis and parameterization. J Geophys Res 100C7:13321-13332

Chamberlin WS, Marra J (1992) Estimation of photosynthetic rate from measurements of natural fluorescence: analysis of the effects of light and temperature. Deep-Sea Res 39: 1695-1706

Chamberlin WS, Booth CR, Kiefer DA, Morrow JH, Murphy RC (1990) Evidence for a simple relationship between natural fluorescence, photosynthesis and chlorophyll in the sea. Deep-Sea Res 37:951-973

Cleveland JS, Weidemann AD (1993) Quantifying absorption by aquatic particles: a multiple scattering correction for grass-fiber filters. Limnol Oceanogr 38:1321-1327

Cleveland JS, Perry MJ, Kiefer DA, Talbot MC (1989) Maximal quantum yield of photosynthesis in the northwestern Sargasso Sea. J Mar Res 47:869-886

Collins DJ, Kiefer DA, SooHoo JB, McDermid IS (1985) The role of reabsortion in the spectral distribution of phytoplankton fluorescence emission. Deep-Sea Res 32:983-1103

Côte B, Platt T (1983) Day to day variations in the springsummer photosynthetic parameters of coastal marine phytoplankton. Limnol Oceanogr 28:320-344

Côte B, Platt T (1984) Utility of the light-saturation curve as an operational model for quantifying the effects of environmental condition on phytoplankton photosynthesis. Mar Ecol Prog Ser 18:57-66

Doerffer R, Sorensen K, Aiken J (1999) MERIS potential for coastal zone applications. Int J Remote Sensing 20: $1809-1818$

Fork DC (1976) Temperature dependence of chlorophyll a fluorescence in algae and higher plants in relation to changes of state in the photosynthetic apparatus. Carnegie Year Book, p 465-472

Furuya K, Takahashi K, Iizumi H (1993) Wind-dependent formation of phytoplankton spring bloom in Otsuchi Bay, a ria in Sanriku, Japan. J Oceanogr 49:459-475

Furuya K, Hayashi M, Yabushita Y (1998) HPLC determination of phytoplankton pigments using N, N-dimethylformamide. J Oceanogr 54:199-203

Garcia-Mendoza E, Maske H (1996) The relationship of solarstimulated natural fluorescence and primary productivity in Pacific waters. Limnol Oceanogr 41:1697-1710

Hoepffner N, Sathyendranath S (1991) Effect of pigment composition on absorption properties of phytoplankton. Mar Ecol Prog Ser 73:11-23 
Jassby AD, Platt T (1976) Mathematical formulation of the relationship between photosynthesis and light for phytoplankton. Limonol Oceanogr 21:540-547

Joint I, Groom SB (2000) Estimation of phytoplankton production from space: current status and future potential of satellite remote sensing. J Exp Mar Biol Ecol 250:233-255

Kawamiya M, Kishi MJ, Kawser-Ahmed MD, Sugimoto T (1996) Causes and consequences of spring phytoplankton blooms in Otsuchi Bay, Japan. Deep-Sea Res 16: 1683-1698

Kiefer DA, Chamberlin WS, Booth CR (1989) Natural fluorescence of chlorophyll $a$ : relationship to photosynthesis and chlorophyll concentration in the western South Pacific gyre. Limnol Oceanogr 34:868-881

Kirk JTO (1994) Light and photosynthesis in aquatic ecosystems. Cambridge University Press, Cambridge

Kishino M, Sugihara S, Okami N (1984) Influence of fluorescence of chlorophyll a on underwater upward irradiance spectrum. La Mer 22:224-232

Kishino M, Takahashi M, Okami N, Ichimura S (1985) Estimation of the spectral absorption coefficients of phytoplankton in the sea. Bull Mar Sci 37:634-642

Kolber Z, Falkowski PG (1993) Use of active fluorescence to estimate phytoplankton photosynthesis in situ. Limnol Oceanogr 38:1646-1665

Lewis MR, Smith JC (1983) A small volume, short-incubationtime method for measurement of photosynthesis as a function of incident irradiance. Mar Ecol Prog Ser 13:99-102

Lizotte MP, Priscu JC (1994) Natural fluorescence and quantum yields in vertically stationary phytoplankton from perennially ice-covered lakes. Limnol Oceanogr 39: $1399-1410$

Mackey MD, Mackey DJ, Higgins HW, Wright SW (1996) CHEMTAX - a program for estimating class abundances from chemical markers: application to HPLC measurements of phytoplankton. Mar Ecol Prog Ser 144:265-283

Mitchell BG, Kiefer DA (1988) Variability in pigment specific particulate fluorescence and absorption in the northeastern Pacific Ocean. Deep-Sea Res 35:665-689

Morel A, Andre JM (1991) Pigment distribution and primary production in the Western Mediterranean as derived and modeled from Coastal Zone Color Scanner observations. J Geophys Res 96:12685-12698

Morel A, Bricaud A (1981) Theoretical results concerning light absorption in a discrete medium, and application of specific absorption of phytoplankton. Deep-Sea Res 11:1375-1393

Owens TG, Falkowski PG, Whitledge TE (1980) Diel periodicity in cellular chlorophyll content in marine diatoms. Mar Biol 59:71-77

Platt T, Sathyendranath S (1988) Oceanic primary production: estimation by remote sensing at local and regional scales. Science 241:1613-1620
Prézelin BB, Tilzer MM, Shofield O, Haese C (1991) The control of the production process of phytoplankton by the physical structure of the aquatic environment with special reference to its optical properties. Aquat Sci 53: 136-183

Ramaiah N, Yoshikawa T, Furuya K (2001) Temporal variations in transparent exopolymer particles (TEP) associated with a diatom spring bloom in a subarctic ria in Japan. Mar Ecol Prog Ser 212:79-88

Schreiber U, Schliwa U, Bilger W (1986) Continuous recording of photochemical and non-photochemical chlorophyll fluorescence quenching with a new type of modulation fluorometer. Photosynth Res 10:51-62

Shaw PJ, Purdie DA (2001) Phytoplankton photosynthesisirradiance parameters in the near-shore UK coastal waters of the North Sea: temporal variation and environmental control. Mar Ecol Prog Ser 216:83-94

Shikama N (1980) Current measurements in Otsuchi Bay. Bull Coast Oceanogr 18:1-8 (in Japanese)

Shikama N (1990) Characteristics in flow field of water in Otsuchi Bay. Otsuchi Mar Res Cent Rep 16:75 (in Japanese)

Smith RC, Baker KS (1981) Optical properties of the clearest natural waters (200-800nm). Appl Opt 20:177-193

Sosik HM (1996) Bio-optical modeling of primary production: consequences of variability in quantum yield and specific absorption. Mar Ecol Prog Ser 93:25-37

Stegmann PG, Lewis MR, Davis CO, Cullen JJ (1992) Primary production estimates from recordings of solar-stimulated fluorescence in the equatorial Pacific at $150^{\circ} \mathrm{W}$. J Geophys Res 97C:627-638

Suggett D, Kraay G, Holligan P, Davey M, Aiken J (2001) Assessment of photosynthesis in a spring cyanobacterial bloom by use of a fast repetition rate fluorometer. Limnol Oceanogr 46:802-810

Suzuki R, Ishimaru T (1990) An improved method for the determination of phytoplankon chlorophyll using $\mathrm{N}, \mathrm{N}$ dimethylformamide. J Oceanogr 46:190-194

Talling JF (1957) Photosynthetic characteristics of some freshwater phytoplankton diatoms in relation to underwater radiation. New Phytol 56:29-50

Tilzer MM, von Bodungen B, Smetacek V (1985) Lightdependence of phytoplankton photosynthesis in the Antarctic Ocean: implications for regulating productivity. In: Sigfried WR, Condy PR, Laws RM (eds) Antarctic nutrient cycles and food webs. Springer-Verlag, Berlin, p 60-69

Uncles RJ, Joint I (1982) Vertical mixing and its effects on phytoplankton growth in a turbid estuary. Can J Fish Aquat Sci 40 (Suppl 1):221-228

Winter DF, Banse K, Anderson GC (1975) The dynamics of phytoplankton blooms in Puget Sound, a fjord in the northwestern United States. Mar Biol 29:139-176 
Appendix 1. Application of Newton's method as a successive approximation of chl a

In order to solve the non-linear Eqs. (9), (14) \& (15) for chl $a$, an iterative technique, Newton's method, was applied. This calculation can be done using spreadsheet software on a PC. The fundamental of Newton's method is shown below.

Assume a non-linear function $f(x)$, which is twice differentiable in the range of $x[a, b]$, and the product $f(a) f(b)<0$. Then there is a value of $x_{1}, \xi$, in the range of $[a, b]$, for which $f(x)=0$ (Fig. A1). At any arbitrary starting point, $x_{0}$, the tangent to the graph of $f(x)$ against $x$ is given by:

$$
y=f\left(x_{0}\right)+\left(x-x_{0}\right) f^{\prime}\left(x_{0}\right)
$$

where $f^{\prime}\left(x_{0}\right)$ is the first derivative of $f(x)$ evaluated at $x=x_{0}$. Over a finite range of $x$ values, this tangent coincides approximately with the curve representing $y=f(x)$. Consequently, if we put $y=0$ and solve for $x$ rearranging, we should get a value $x_{1}$ that is nearer the solution than $x_{0}$ :

$$
x_{1}=x_{0}-f\left(x_{0}\right) / f^{\prime}\left(x_{0}\right)
$$

and more generally:

$$
x_{n+1}=x_{n}-f\left(x_{n}\right) / f^{\prime}\left(x_{n}\right)
$$

i.e. we obtain the accurate approximation, $x$, by repeating the above procedure as many times as necessary. However, sometimes this does not happen and approximations get worse and worse, if calculation is started with an inappropriate initial value.

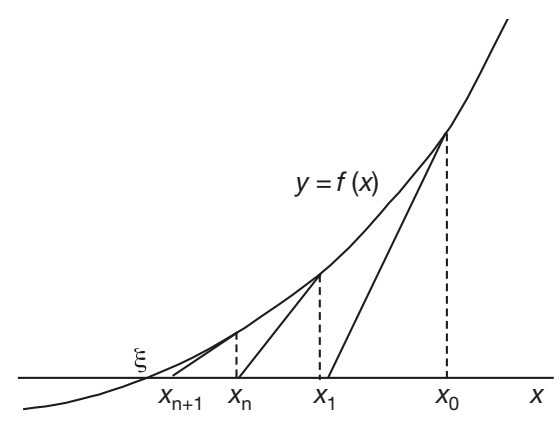

Fig. A1. Graphical illustration of Newton's method for solving the equation $f(x)=0 . x_{0}$ : an arbitrary starting point, $x_{1}$ : the intersection point of the tangent to the curve of $y=f(x)$ at $x=x_{0}$ and the $x$-axis
In the present study, the general expression for Eqs. (9), (14) \& (15), $g(\mathrm{chl} a)$ and its first derivative $g^{\prime}(\mathrm{chl} a)$, are:

$g(\operatorname{chl} a)=\mathrm{p}+\mathrm{q} \operatorname{chl} a+\mathrm{r} E_{\mathrm{PAR}}^{\circ} / L_{\mathrm{u} \mathrm{chl}} \mathrm{chl} a^{\mathrm{s}}+\mathrm{t} E_{\mathrm{PAR}}^{\circ} / L_{\mathrm{u} \mathrm{chl}} \mathrm{chl} a^{\mathrm{s}+1}$ $g^{\prime}(\mathrm{chl} a)=\mathrm{q}+\mathrm{r} \mathrm{s} E_{\mathrm{PAR}}^{\circ} / L_{\mathrm{u} \mathrm{chl}} \mathrm{chl} a^{\mathrm{s}-1}+\mathrm{t}(\mathrm{s}+1) E_{\mathrm{PAR}}^{\circ} / L_{\mathrm{u} \mathrm{chl}} \mathrm{chl} a^{\mathrm{s}}$ Here $p, q, r, s, t$ are the constants. The solution $x$ is determined for each measured value of $E_{\text {PAR }}^{\circ}$ and $L_{\mathrm{u} \text { chl }}$. Consider, for example, with Eq. (9), in which (p, q, r, s, t) $=(7.41,0.138$, $0,-0.50,-0.00053)$. The solutions $\xi=0.4,2.0,10$ are given when the ratio $E_{\mathrm{PAR}}^{\circ} / L_{\mathrm{u} \mathrm{chl}}=2.22 \times 10^{4}, 1.02 \times 10^{4}, 5.23 \times 10^{3}$, respectively (Fig. A2). If one starts the calculation with an initial value of $\mathrm{chl} a_{0}=4.0, \mathrm{chl} a_{1}$ get closer to the solutions in the cases of $\xi=2.0,10$. However, it results in failure in the case of $\xi=0.4$, because a negative value of chl $a_{1}$ is given, and the last term of $g\left(\mathrm{chl} a_{1}\right)$ becomes an imaginary, fractional power of the negative number. This failure in the approximation is due to the phenomena that the slope of the tangent line gets smaller as chl a increases. However, if one starts with a low value of chl $a_{0}=0.2$, chl $a_{1}$ gets closer to the solution in all these curves. Therefore, we used the initial value of chl $a_{0}=0.2$ for all data, which gave the accurate approximations within 10 time repeats (the residua becomes $<0.001)$.

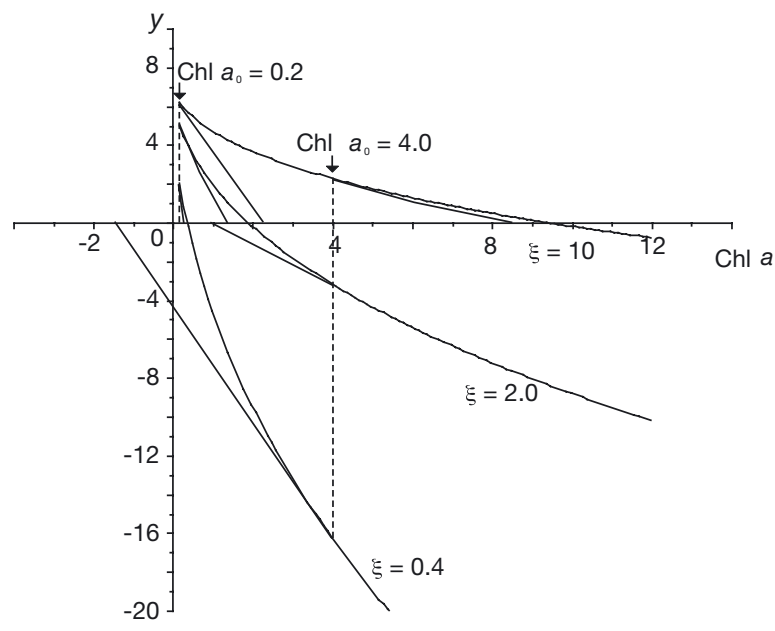

Fig. A2. Examples of the applications of Newton's method in the present study
Editorial responsibility: Osmond Holm-Hansen (Contributing Editor), La Jolla, California, USA
Submitted: December 17, 2002; Accepted: October 31, 2003 Proofs received from author(s): May 24, 2004 